\title{
LXIV. Temperature of inversion of the Joule- Kelvin effect for air and nitrogen. Preliminary communication
}

\section{K. Olszewski}

To cite this article: K. Olszewski (1907) LXIV. Temperature of inversion of the Joule-Kelvin effect for air and nitrogen. Preliminary communication , Philosophical Magazine Series 6, 13:78, 722-724, DOI: $10.1080 / 14786440709463651$

To link to this article: http://dx.doi.org/10.1080/14786440709463651

曲 Published online: 16 Apr 2009.

Submit your article to this journal $₫$

Џll Article views: 2

Q View related articles $\longleftarrow$

Citing articles: 1 View citing articles $\square$ 


\section{[ 722$]$}

LXIV. Temperature of Inversion of the Joule-Kelvin Effect for Air and Nitrogen. Preliminary Communication. By K. Olszewski *.

TN a paper published by me five years ago $t, I$ had de1 termined the inversion temperature of the Joule-Kelvin effect to be $-80^{\circ} .5$ for hydrogen; this figure has proved to be of fundamental importance in the design of liquefying apparatus $\ddagger$ for this gas. The paper mentioned has also attracted the attention of physicists, and A. W. Porter $\S$ has made use of it in a theoretical investigation of the accuracy of van der Waals's and Dieterici's state equations, based on my determination of the inversion temperature. On account of the great theoretical importance of such determinations, I have decided to carry out similar measurements for other gases, and above all for air and its more important components. Up to the present, I have only completed the experiments on the inversion temperatures for air and atmospheric nitrogen, and take the opportunity of presenting the results in a brief notice, reserving a detailed description of the experimental arrangements and the apparatus for a later communication. I only wish to remark that the apparatus used did not differ in principle from that employed by me five years ago, but that in view of the high temperature (up to $300^{\circ}$ ) at which the experiments on air and nitrogen had to be carried out, considerable modifications in the details as well as in the dimensions became necessary.

As Witkowski, as far back as $1898 \|$, and, last year, Porter $\S$, on theoretical grounds came to the conclusion that the inversion temperature of the Joule-Kelvin effect for gases was a function of the pressure, $I$ have in the present experiments devoted special attention to the initial pressures of the gases which were made to undergo an irreversible expansion.

The apparatus was heated in an oil-bath. Temperatures were measured with a high-reading mercury thermometer ; but for the purpose of determining the small temperature changes which occur during expansion, an iron-constantan thermo-couple was used, whose sensitiveness was about $0^{\circ} \cdot 2$ per mm. of galvanometer scale.

The gas, which had been compressed to the initial pressure $p$, was allowed to expand down to one atmosphere. The experiment was repeated a number of times under these conditions, the temperature of the gas being gradually reduced

* Communicated by the Author. (Bull. Acad. Crac. Nov. 1906.)

† K. Olszewski, Bull. Ac. Crac. 1901, p. 453; Phil. Mag. [3] p. 535(1902).

$\ddagger$ K. Olszewski, Bull. Acad. Crac. 1902, p. 625, and 1903, p. 241.

\$ A. W. Porter, Phil. Mag. [6] xi. p. 554 (1906).

II A. W. Witkowski, Bull. Acad. Crac. 1898, p. 282. 
Temperature of Inversion of the Joule-Kelvin Effect. $\quad 723$ from $+300^{\circ}$. Above a certain temperature $t_{i}$ the thermocouple showed a heating of the gas, below this temperature an unmistakable cooling, and at the temperature $t$ itself the integral result of the Joule-Kelvin effect was zero.

In the following table are given the initial pressures $p$ (expressed in $\mathrm{kg}$. per sq. $\mathrm{cm}$.) and the corresponding temperatures of inversion $t_{i}$.

\begin{tabular}{|c|r|r|r|}
\hline \multicolumn{2}{|c|}{ AIR. } & \multicolumn{2}{|c|}{ NItrog IN. } \\
\hline$p$. & $t_{i .}$ & $p$. & $t_{t .}$ \\
\hline 160 & +259 & 159 & +243 \\
100 & 249 & 126 & 238 \\
90 & 244 & 102 & 233 \\
80 & 240 & 90 & 228 \\
70 & 235 & 80 & 223 \\
60 & 226 & 68 & 217 \\
40 & 198 & 55 & 205 \\
20 & 124 & 30 & 163 \\
& & & \\
\hline
\end{tabular}

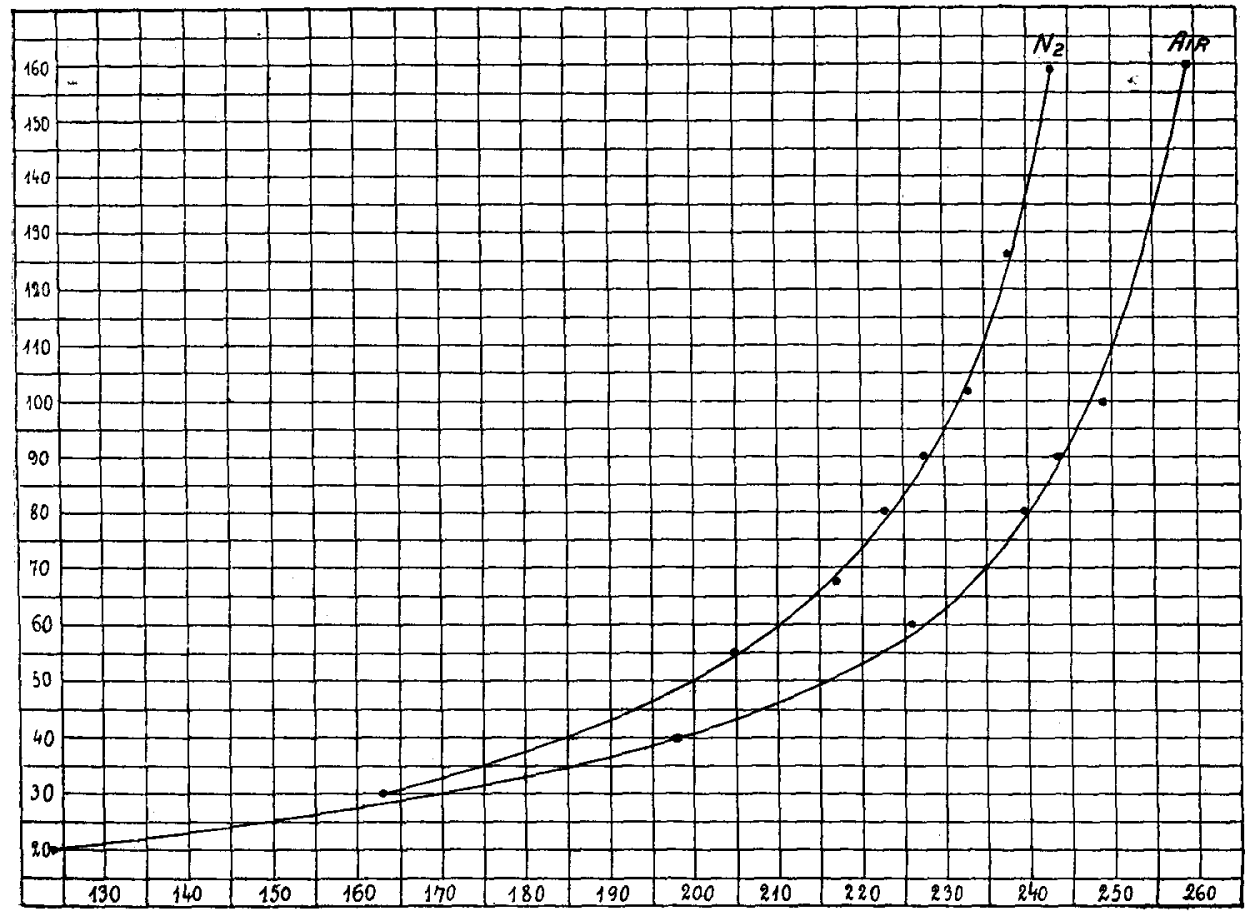

In the accompanying figure the experimental results are represented graphically, the initial pressures $p$ (kg./sq. cm.) 


\section{Prof. A. W. Porter on the Isopiestic Temperatures}

being used as ordinates and the corresponding inversion temperatures $t_{i}$ as abscisse. The curve thus represents the relation connecting the inversion temperature of the gas under consideration with its initial pressure. The curves fully confirm the conclusion of Witkowski and Porter that the inversion temperature is a function of the pressure. The values of the inversion temperature for air calculated by Witkowski by the aid of the empirical formula given by RoseInnes $\left(+360^{\circ}\right)$, and by means of that of van der Waals $\left(+500^{\circ}\right)$ are, it is true, somewhat high when compared with those obtained by myself; but it must be remembered that the second value $\left(+500^{\circ}\right)$ was calculated on the assumption of a small pressure-difference ( 1 atmo.), whereas my figures refer to the integral value of the Joule-Kelvin effect when a gas expands from a high pressure to 1 atmo.

In conclusion, I would refer to the connexion which appears to exist between the shape of the curve for air and the behaviour of this gas in a liquefying apparatus. By means of the apparatus described by me in $1902 *$, which I am in the habit of using at lectures for the demonstration of the liquefaction of air, it is easy to show that liquefaction takes place only so long as the initial pressure does not fall below 80 atmos.; a further expansion from pressures which are below 80 atmos. is entirely without result. From the accompanying figure it is seen that precisely at the point corresponding to a pressure of 80 atmos. the curve takes a sharp bend, and that at this point a sudden drop takes place in the temperature of inversion, whereby also the cooling effect rapidly decreases, the behaviour of air beyond this point approaching in this respect more and more nearly that of hydrogen, whose inversion temperature is very low.

Chemical Institute of the Jagellon University, Cracow.

LXV. On the Isopiestic Temperatures of Saturated Vapours of Different Substances. By AlFred W. Porter, B.Sc., Fellow of, and Assistant Professor of Physics in, University College, London $\dagger$.

T $\mathrm{N}$ the Philosophical Magazine for Jan. 1886 Ramsay and Young published a law (known by their names) counecting the temperatures at which different saturated vapours have the same vapour-pressure. The law has been employed in two somewhat different forms. One only of these forms

* K, Olszewski, Bull. Acad. Crac. 1902, p. 623.

+ Communicated by the Author. 